\title{
THE TRANSITION OF REGISTRY SYSTEM IN THE DEVELOPED COUNTRIES
}

\author{
Siti Khairunnisa Sheikh Abdul Mutalib ${ }^{1 \star}$, Siti Nur Shahira Dahari ${ }^{2}$ \\ ${ }^{1}$ Ms., Northumbria University Newcastle, The United Kingdom, siti.mutalib@northumbria.ac.uk \\ ${ }^{2}$ Ms., Durham University, The United Kingdom, dahari.s.shahira@durham.ac.uk \\ ${ }^{*}$ Corresponding author
}

\begin{abstract}
The registry is a record system that helps government departments to link between content, context and the structure of records in improving information management (record keeping system). In the government of Malaysia, there are examples of a poor registry system which affects the availability of records as evidence and information. To illustrate, Malaysia lost Batu Puteh Island to Singapore in 2008 because there were insufficient records found as evidence in court. The hydrological disasters affected one of the states in Kelantan, Malaysia; including state government department on 2014 has affected the loss of government records. This paper shares the literature for the transition of the registry system in the government sector specifically developed countries. The transition is a process of change happened in the registry system. This paper seeks to identify the transition process of the registry system as one of the predominant record keeping systems in the developed countries. The registry system is an audit trail for better record tracking. The implementation of the registry has improved the efficiency of record keeping in the government sector. This paper aims to discuss the management of registry in the government sector by understanding the nature and functions in implementing the registry. The paper looks at the problems presented by the registry system focusing in the government sector. It considers a definition of registry, and discusses the essentials of registry system. However, research work needs to be carried out to formulate the best practices in managing and implementing the registry. The most important thing is to ensure that the registry helps the government sector from record loss and consistent throughout every government agencies. To cover registry system in a comprehensive method, it is not only focusing on nature and functions, but the filing classification also needs to be concentrated. Filing classification is the main tools to ensure the accurate process of searching and retrieving the file in the registry. This conceptual paper could potentially contributes to the preparation of implementing the registry system in the government sector.
\end{abstract}

Keywords: Registry Information Management (record keeping system), Transition Registry, Audit Trail, Classification Scheme, Registry Filing Systems

\section{INTRODUCTION}

It is impossible to understand the records management without understanding registry filing systems (Stephens, 1995). The registry system can be implemented across multiple sites/locations but those aspects 
relating to the logical control of records must remain centralised (policy, procedures etc. and managing the classification plan) (AMRS,2010). The history of registry filing systems started in the $13^{\text {th }}$ century, when British government implemented a formal system to register incoming and outgoing government documents in a book or register (Stephens, 1996). According to Stephens (1995), the registry filing system has been disseminated by the British government throughout the world. The British implemented the registry filing system in the government, especially in the Civil Services and colonies throughout their worldwide empire. Now, registry filing systems are used as the most significant and basic system in record keeping in Europe, Africa, Asia and the South Pacific.

The term registry, register and registration are related but have unique meanings in English registry filing systems. According to Stephens (1996), the term registry is referring to the physical location to place the document like file room. However, the term register can be classified into two; noun which referring to a physical to index and record the documents and verb which referring to the activity of locating a registered document on file. The term registration is a filing activity of a document as an official record.

The term registry is a common term used in records management. The term registry can be defined as records office where in charge for the receipt, control and maintenance of current records (IRMT, 1999). Besides, the main function of a registry is to house the entire series of records kept in a particular organization and to have intellectual control over the records. The methods of the registers can be books, cards and electronic formats like Microsoft Word, Excel and system application. This paper is to provide a preliminary view on managing registry system in the government sector which can help from record loss.

\section{REGISTRY AND REGISTRY FILING SYSTEM NATURE}

The registry filing system is a system used to capture and link the context of the records with their content. The main function of registries is well described by Craig (2002) where it is discussed by agreed procedures to complete control records achieved by processes for managing their use, location, order, and contents. The registry is a system which helps users and the organization to a link between content (the records), context (the storage) and the structure (methods of displayed) of records in improving record keeping system as an audit trail. In addition, the main characteristic of the registry filing system is the method used to capture and list the receipt and movement of records that are actively used in the organization.

There are two types of the registry in the record keeping which are centralized and decentralized registries. The centralized registry is a registry for all divisions and the decentralized registry is a registry that based in every department of the civil service in the United Kingdom (Craig, 2002). Centralized and decentralized registries each have advantages and disadvantages. The advantage of centralized is there is an intellectual control over the records created because of the standard and centralized regarding policy, mail operations, classification scheme, procedural practices, and the retention and disposal schedule. Moreover, the security of centralized registry is easy to maintain because the records are stored at the same location. However, the advantages of the decentralized registry are in terms of speeding retrieval process due to small location and small numbers of records. Nevertheless, Craig (2002) stated the central registry has obstacles in communication between Central Registry staff and division staffs. The division staffs prefer to have their own clerk to handle the records since the clerk has better understanding on the subject and the flow of the records in the division.

In British government, some departments run centralized registries; others have decentralized registries according to the divisions or branches (Stephens, 1996). The concept is slightly similar with Malaysia the British colony. Malaysian government currently applies centralized registry in the ministry. However, the centralized registry is focusing on open access records. Yet, the decentralized registry has been implemented through the department or division in the ministry to manage the classified records (confidential, secret and top secret) and names as a file room. However, in German, there is one registry for each division in a ministry. The registry is responsible to classify the records according to the standard registry classification scheme (Stephens, 1995).

\section{THE FUNCTIONS OF REGISTRY FILING SYSTEMS}

The functions of registry filing system are to index and control the records before any processing takes place in the organization (Stephens, 1995). However, the key functions of registry filing system are indexing, controlling and tracing the movement of the records. Moreover, it creates and captures the records as evidence in a business transaction and provide link between the records during the retrieval process in the organisation (Packalen \& Henttonen, 2015).

The process of indexing and classifying the records are fundamental. The vocabulary control process is to ensure the records can be accessed and retrieved by the users efficiently. According to Henttonen (2012), 
one of the classification schemes in records and archive management happened in the registry. This is complied with the registry function to serve information from registered records. According to Lindh (1993), the registry filing system helps to establish the original order and return the documents to their exact location. Besides making the records available for business transaction and evidence, the major function of registry filing system in the government is to help it to maintain the corporate memory which has a high value towards the country.

\section{REGISTRY CLASSIFICATION SCHEME}

The registry system includes a classification file that assists the public servant in retrieving the records accurately and efficiently. The British in the registry filing system have adopted many trial and error practices. The registry filing system in British has been improved by 20th century where the system has been designed to solve the problems of office work instead to be the storage for the records (Craig, 2002). After restructured, the government decided to identify the subject of the records upon receipt at the registry. Moreover, the process of sorting the records has been changed from physical object to the subject classification order (Craig, 2002).

England started a formal registry filing system for government documents in the 13th century by using the incoming and outgoing classification (Stephens,1995). The change has related with recognition from the government on the real control over the records. The procedures also changed at the beginning of the registry. The classification and indexing of the records has been completed when the papers were filed away at the conclusion of the business. By 1946, the British government has decided to create a division of records into unofficial, semi-official and official where it has been used until now in any records management field throughout the world (Craig, 2002).

In Iceland, there were two registry systems used at the early implementation which is; 'rentukammerkerfi' and 'kansellikeffi'. 'Rentukammerkerfi' is the process of registering the incoming letter without considering the content and kansellikeffi' is the process of registering letter according to the subject or sender. However, these systems have been supplanted by a numeric-subject system (based on letter subject) and numeric system (based on division, group, and sub-group) (Gunnlaugsdottir, 1999).

In German, the files classification schemes which a four-level/digit hierarchical system has been used. The files have been classified according to hierarchy designate. The primary subject is located at the top of the hierarchy designate, followed by the main functions or activities of an organization, categories and the individual files units (Stephens, 1995).

The filing classification in Government of Malaysia started since 1986 when MAMPU (Malaysian Administrative Modernisation and Management Planning Unit) published The Guideline Filing System for Government Agencies Malaysia. The Guideline is to persuade the government agencies to develop classification file based on subject classification and coding. However, in the year 2003, National Archives of Malaysia has been received a mandate from Government of Malaysia to have an authority in managing archives and records for the public sector in Malaysia according to National Archives Act 2003 (Act 629) (Malaysia, 2003). National Archives of Malaysia has improvised the filing system by MAMPU and introduced the block numeric system. The new system is focusing on housekeeping or facilitative file based on Circular Number 5 The year 2007, Subject 7.4. In the year 2008, National Archives of Malaysia being the first agency in Malaysia using Electronic Records Management System (TRIM Software is also known as HP Records Manager). The classification file that has been developed for the system called a Functional Classification File. This Functional Classification File was referring to ISO 15489 (Malaysia Standard MS 2223:2009) (Shafie, 2017). Moreover, National Archives of Malaysia has published The Developing Classification File Guidelines for Public Sector June 2012 to encourage users to use the functional classification file among public servant. In the year 2015, Digital Document Management System (DDMS) has been implemented and accepted as an electronic registry. It has been used by 33 ministries and government agencies in Malaysia.

Likewise, the classification scheme is a fundamental for an effective registry. It assists in the process of searching and retrieving the records by locating the records with a similar theme together and to identify the ownership of the records.

\section{THE CHALLENGES OF REGISTRY SYSTEMS}

The advantage of the registry filing system is when the records have been classified at the early capturing process before sent to the recipient. However, Morddel (1989) stated even the British government, colonies and ex-colonies had implemented dozens of registries but none of them fully works and able to cope with a number of paper files' stores. In contrast, the registry has been changed from traditional registry and paperbased records to the electronic registry and electronic records. By that, the challenge is not only focusing on 
the paper-based records, but the biggest challenge in the registry filing system is currently to link it with Electronic Documents and Records Management System (EDRMS). Moreover, other challenges are to ensure the correct metadata for different formats of records and person responsible to handle the registry systems. According to Tough (2003), with the upcoming of registry system and the use of software, the staff that handles the registry filing system need to be trained. This makes some organizations facing the challenge of providing training from their own resources.

The strength in the registry filing system relies on the level of service provided for the users and users' satisfaction towards on filing system. According to (Packalen \& Henttonen, 2015) a registry may be disorganized and poorly equipped with insufficient manpower. The issues are files cannot be retrieved, and information is unavailable. By that, the government as a whole is liable to duplication of effort and poor decision making. All the major problems identified above are evidence, and the main point tackled before the old registry could be transformed into a new records office.

\section{CONCLUSION}

In a conclusion, the main function of the registry is as an audit trail for the government sector to trace and use the records in their business processes and future reference in any circumstances. The successful of the registry system is relying on the sufficient and skillful registry staff, a better filing system and the classification schemes. Moreover, the registry is to ensure the records have been captured and refined in the registry system to address a broader range of record keeping needs and to help the government from record loss. This paper will provide a preliminary indication to the record keeping practitioners in the registry system.

\section{REFERENCE LIST}

Craig, B. L. (2002). Retinking Formal Knowledge and its Practices in the Organizaton: The British Treasury's Registry between 1900 and 1950*. Archival Science, 2, 111-136.

Gunnlaugsdottir, J. (January 01, 1999). Records Management in Iceland. Information Management Journal Prairie Village-, 33, 4, 32-37.

Malaysia Law: National Archives Act 2003 (Act 629) § 8 (2003).

Morddel, A. (1989, April). Forget Philosophy, Torch the Registry. Records Management Quarterly, 52-54.

Packalen, S., \& Henttonen, P. (2015). Recordkeeping Professionals' Understanding of and Justification for Functional Classification : Finnish public sector organizational context. Archival Science, 1-17.

Shafie, S. (2017, January 31). Klasifikasi Fail di Sektor Kerajaan Malaysia. Kuala Lumpur, Malaysia.

Stephens, D. O. (1996). Records management in the United Kingdom: Part III--English registry filing systems. Records Management Quarterly, 30(2), 73.

Stephens, D. O. (1995). The registry: The world's most predominant recordkeeping system. Records Management Quarterly, 29(1), 64.

Tough, A. (2003). Records Management Standards and The Good Governance Agenda in Commonwealth Africa. ESARBICA, 22, 2-15.

United Nations (Archives and Records Management Section). 2010. Recordkeeping Toolkit for Peacekeeping Operations: Registries. 